Kinga SKUBISZ1 ${ }^{1}$, Marek SZCZOTKA ${ }^{2}$

DOI: https://doi.org/10.53052/9788366249837.22

\title{
OBCIĄŻENIA ŁADUNKU WYWOŁANE FALOWANIEM OKRĘTU
}

\begin{abstract}
Streszczenie: W pracy przedstawiono opis modelu i programu komputerowego służącego do wyznaczaniu obciążeń wywołanych kołysaniem statku transportującego ładunki. Przedstawiono przykładowe lokalizacje punktów, dla których prowadzono obliczenia uwzględniając charakterystyki rzeczywistej jednostki pływającej. Wyniki przestawiono w formie wykresów przyspieszeń, będących rezultatem przyjętego modelu falowania oraz odpowiedzi jednostki, jak również w postaci przebiegów sił reakcji.
\end{abstract}

Słowa kluczowe: jednostka pływająca, kołysanie okrętu, obciążenia pokładu i ładunków

\section{CARGO LOADS INDUCED BY SHIP MOTIONS DUE TO WAVES}

Summary: The paper presents a model and a computer programme for determining the loads caused by ship motions during transportation of the objects. Example loads/locations are assumed for points for which the calculations are carried out. An actual ship characteristics was used to prescribe its motions. The results presented as acceleration and force graphs generated for each considered location shows the response due to a sea wave model assumed.

Keywords: vessel, ship motions, deck loads, cargo loads

\section{Wprowadzenie}

Transport morski odgrywa znaczącą rolę w gospodarkach wielu krajów na świecie. Od tysięcy lat tą metodą odbywała się wymiana handlowa, powstawały nowe drogi morskie oraz była to jedyna metoda przemieszczania się na znaczne odległości. Statki mogły zapewnić bezpieczny transport towarów. Nie bez znaczenia jest wpływ tej gałęzi na rozwój ludzkości, zapoczątkowany wiele wieków przed erą nowożytną. Budowa morskich środków transportu jest stosunkowo wąską i specyficzną działalnością skoncentrowaną wokół istniejących od dziesięcioleci (lub dłużej) ośrodków portowych. Stocznie i biura projektowe okrętów rozwijają swoją działalność często jako rodzinne, wielopokoleniowe przedsiębiorstwa. Ogromna większość z tych firm posiada odpowiednie know-how, doświadczenie oraz patenty

1 inż. Akademia Techniczno-Humanistyczna w Bielsku-Białej, Wydział Zarządzania i Transportu, studentka II stopnia na kierunku Transport, email kinga.skubisz@icloud.com ${ }^{2}$ dr hab. inż., prof. ATH, Akademia Techniczno-Humanistyczna w Bielsku-Białej, Wydział Zarządzania i Transportu, email mszczotka@ath.edu.pl 
umożliwiające dostarczanie nowych projektów dla większości powstających okrętów budowanych na całym świecie. Ciekawostką jest, że dotyczy to stosunkowo niedużych podmiotów (wyspecjalizowanych biur projektowych) np. z Norwegii, Holandii czy Stanów Zjednoczonych.

Ze względu na specyficzne warunki morskie, jednostki pływające posiadają odpowiednie cechy. Pierwszorzędną kwestią jest bezpieczeństwo żeglugi w warunkach sztormowych. Niemniej istotna jest stabilność oraz manewrowość, również w warunkach utraty funkcjonalności pewnych systemów lub utraty części ładunku. Kolejnym aspektem jest zapewnienie wymaganych własności jednostki pływającej poprzez kształtowanie odpowiednich charakterystyk odpowiedzi na wymuszenia [1] spowodowane warunkami panującymi na morzu, takimi jak fale, wiatr czy prądy morskie.

W niniejszej pracy przedstawiono przykładowe obliczenia dotyczące parametrów ruchu wybranych punków usytuowanych na jednostce pływającej. Analizie poddano jednostkę wykonującą specjalistyczne prace na morzu, takie jak instalacje morskich farm wiatrowych, prace związane $\mathrm{z}$ obsługą infrastruktury służącej w procesie transportu i wydobycia zasobów naturalnych czy prace związane z przeładunkiem towarów i urządzeń na morzu. Analizę prowadzono pod kątem wyznaczania obciążeń obiektów transportowanych statkiem, co jest podobne do procesu wyznaczania sił oddziaływania na pasażerów/członków załogi, wywołanych efektem falowania statku. Wyniki zobrazowano w formie wykresów przyspieszeń oraz sił w punktach mocowania ładunków.

\section{Wyznaczanie ruchu jednostki pływającej w warunkach falowania}

\subsection{Opis ruchu statku}

W wielu praktycznych zastosowaniach przyjmuje się opis ruchu statku podając sześć współrzędnych uogólnionych, które definiują jednoznacznie położenie i orientację kadłuba (traktowanego jako bryła sztywna) w sposób następujący (rysunek 1):

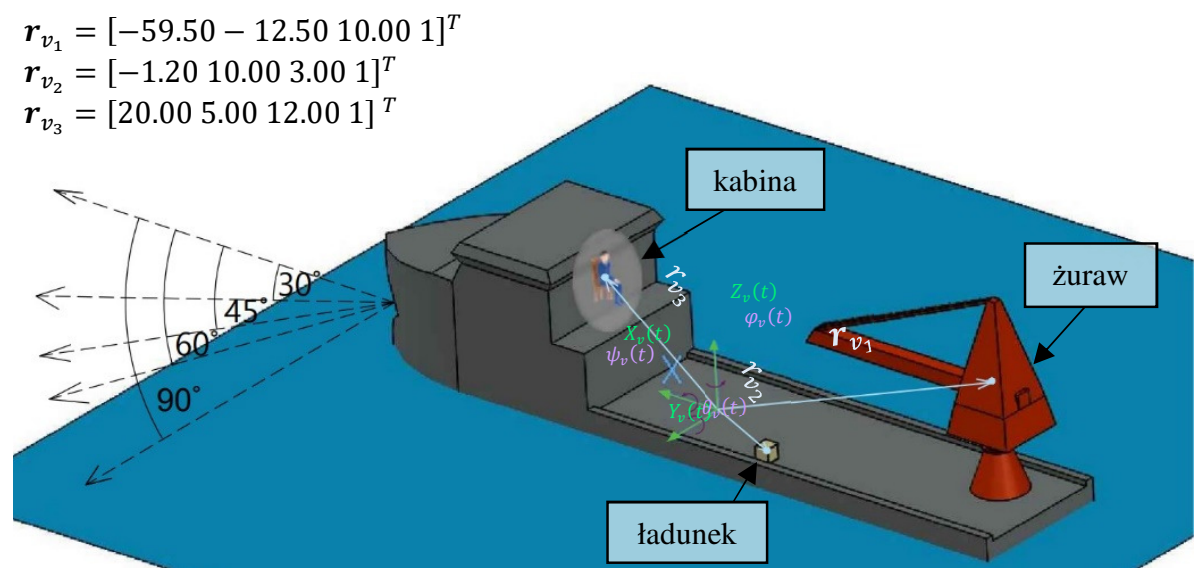

Rysunek 1. Układy wspótrzędnych i definicje lokalizacji obiektów

$$
\boldsymbol{q}_{v}(t)=\left[\begin{array}{ll}
\left(\boldsymbol{X}_{\boldsymbol{v}}(t)\right)^{T} & \left(\boldsymbol{\Omega}_{v}(t)\right)^{T}
\end{array}\right]
$$


gdzie: $\quad \boldsymbol{X}_{v}(t)=\left[\begin{array}{lll}x_{v}(t) & y_{v}(t) & z_{v}(t)\end{array}\right]^{T}, \boldsymbol{\Omega}_{v}(t)=\left[\begin{array}{llll}\psi_{v}(t) & \theta_{v}(t) & \varphi_{v}(t)\end{array}\right]^{T}$, $x_{v}(t), y_{v}(t), z_{v}(t)$ są przemieszczeniami liniowymi statku, $\psi_{v}(t), \theta_{v}(t), \varphi_{v}(t)$ są kątami obrotu jednostki (rysunek 1).

W celu powiązania ruchu jednostki (składowych wektora $\boldsymbol{q}_{v}$ ) z charakterystykami amplitudowo-częstotliwościowymi (ang. RAO - Response Amplitude Operators), należy uwzględnić ich postaci, tj.

$$
\left(\boldsymbol{R A O}\left(\omega, \beta_{k}\right)\right)_{i=1, \ldots, 6}=\left\{F_{k, i}\left(\omega, \beta_{k}\right), \Gamma_{k, i}\left(\omega, \beta_{k}\right)\right\}, k=1, \ldots, n_{\beta}
$$

gdzie: $\omega$ - częstość spotkaniowa,

$\beta_{k}$ - kąt natarcia fali $\left(n_{\beta}\right.$ liczba rozważanych kątów natarcia fali),

$F\left(\omega, \beta_{k}\right), \Gamma\left(\omega, \beta_{k}\right)$ - charakterystyka amplitudowa i fazowa.

Po uwzględnieniu (1) oraz (2), wprowadzając do opisu model nieregularnego falowania morza, można współrzędne wektora $\boldsymbol{q}_{v}$ zapisać w postaci:

$$
\left(\boldsymbol{q}_{v}\right)_{i=1 . .6}=\sum_{j=1}^{N} F_{k, i}\left(\omega, \beta_{k}\right) \cdot \zeta \cdot \cos \left(-\omega_{j} t+\tau_{j, k}+\Gamma_{\mathrm{k}, \mathrm{i}}\left(\omega_{j}, \beta_{k}\right)\right)
$$

gdzie: $\quad \tau_{j, k}=k_{j} x_{p} \cos \left(\beta_{k}\right)-k_{j} y_{p} \sin \left(\beta_{k}\right), H_{s}$ - znacząca wysokość fali,

$\omega_{p}$ - częstość szczytowa spectrum falowania,

$\zeta\left(t, x_{p}, y_{p}, S_{\omega}\right)=\sum_{j=1}^{N} \zeta_{j} \cdot \cos \left(-\omega_{j} t+\tau_{j, k}+\kappa_{j}\right)$,

$\zeta_{j}=\sqrt{2 S_{\omega} \cdot\left(\omega_{j}-\omega_{j-1}\right)}, k_{j}=g^{-1} \omega_{j}^{2}, N=4000$

$S_{\omega}\left(\omega, H_{s}, \omega_{p}\right)=\frac{A_{\gamma} \cdot 5}{16} H_{s}^{2} \omega_{p}^{4} \omega^{-5} e^{\left(-\frac{5}{4}\left(\frac{\omega}{\omega_{p}}\right)^{-4}\right)} \gamma^{e^{-0.5\left(\frac{\omega-\omega_{p}}{\sigma \omega}\right)}}$,

$\gamma$ - współczynnik zależny od modelu falowania,

$\sigma=\left\{\begin{array}{l}0.07 \\ 0.09\end{array}\right.$ gdy $\begin{array}{c}\omega \leq \omega_{p} \\ \omega>\omega_{p}\end{array}, A_{\gamma}=1-0.287 \ln (\gamma)$,

$\kappa_{j}$ - losowa wartość przesunięcia fazowego, $\kappa_{j} \in[0,2 \pi]$.

Uzyskując wartości liczbowe wektora $\boldsymbol{q}_{v}$ współrzędne globalne punku określa wzór:

$$
\boldsymbol{r}_{p, j}=\boldsymbol{B}_{v}\left(\boldsymbol{q}_{v}\right) \cdot \boldsymbol{r}_{v, j}
$$

gdzie: $\quad \boldsymbol{r}_{p, j}$ - położenia punku $j$ związanego ze statkiem w układzie globalnym,

$\boldsymbol{r}_{v, j}$ - współrzędne punku $j$ w układzie lokalnym statku (rysunek 1),

$\boldsymbol{B}_{v}\left(\boldsymbol{q}_{v}\right)$ - macierz przekształcenia jednorodnego dla statku [2].

Zgodnie ze wzorem (4), prędkości $\dot{\boldsymbol{r}}_{p, j}$ i przyspieszenia $\ddot{\boldsymbol{r}}_{p, j}$ oblicza się podobnie, zastępując macierz $\boldsymbol{B}_{v}$ z (4) odpowiednimi pochodnymi [2], tj., $\dot{\boldsymbol{B}}_{v}=\frac{d \boldsymbol{B}_{v}}{d t}$ oraz $\ddot{\boldsymbol{B}}_{v}=\frac{d^{2} \boldsymbol{B}_{v}}{d t^{2}}$. Generowanie tych macierzy (zależnych od $\boldsymbol{q}_{v}$ ) zaimplementowanow programie komputerowym.

\subsection{Program komputerowy}

Dla zautomatyzowania procesu obliczeń opracowano program komputerowy korzystając z bibliotek MFC (Visual C++), którego zadaniem są szybkie obliczenia wariantowe. Na rysunku 2 przedstawiono zrzut ekranu głównego tego programu. 


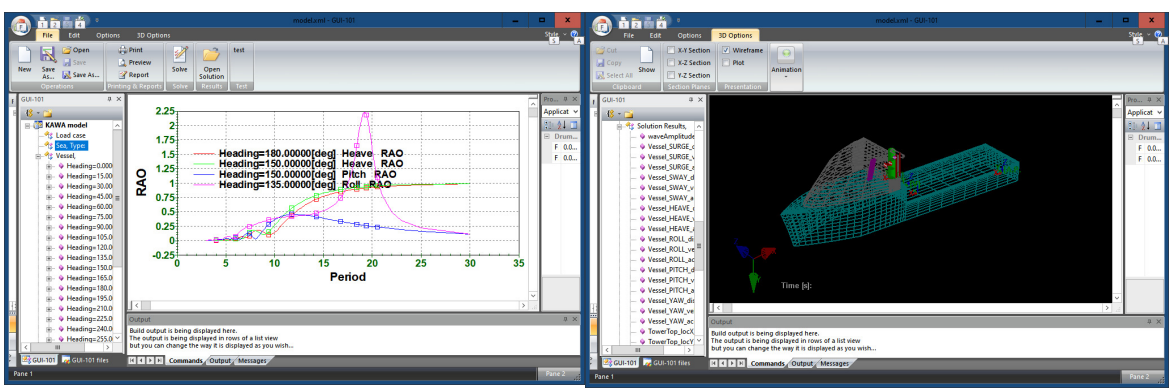

Rysunek 2. Program komputerowy do generowania parametrów ruchu statku

Program umożliwia m.in.:

- Transformację charakterystyk amplitudowo-częstotliwościowych statku,

- Definicję warunków pogodowych (modele fal nieregularnych, regularnych),

- Definicję obiektów, dla których wykonywane są obliczenia,

- Eksport wyników w celu dalszej pracy w innych programach,

- Generowanie przebiegów czasowych ruchu jednostki,

- Obliczanie przebiegów częstotliwościowych odpowiedzi układu,

- $\quad$ Wbudowany moduł wykresów oraz animację ruchu statku w OpenGL.

$\mathrm{Na}$ rysunku 3 przedstawiono typowy proces generowania wyników przy użyciu opracowanego programu.

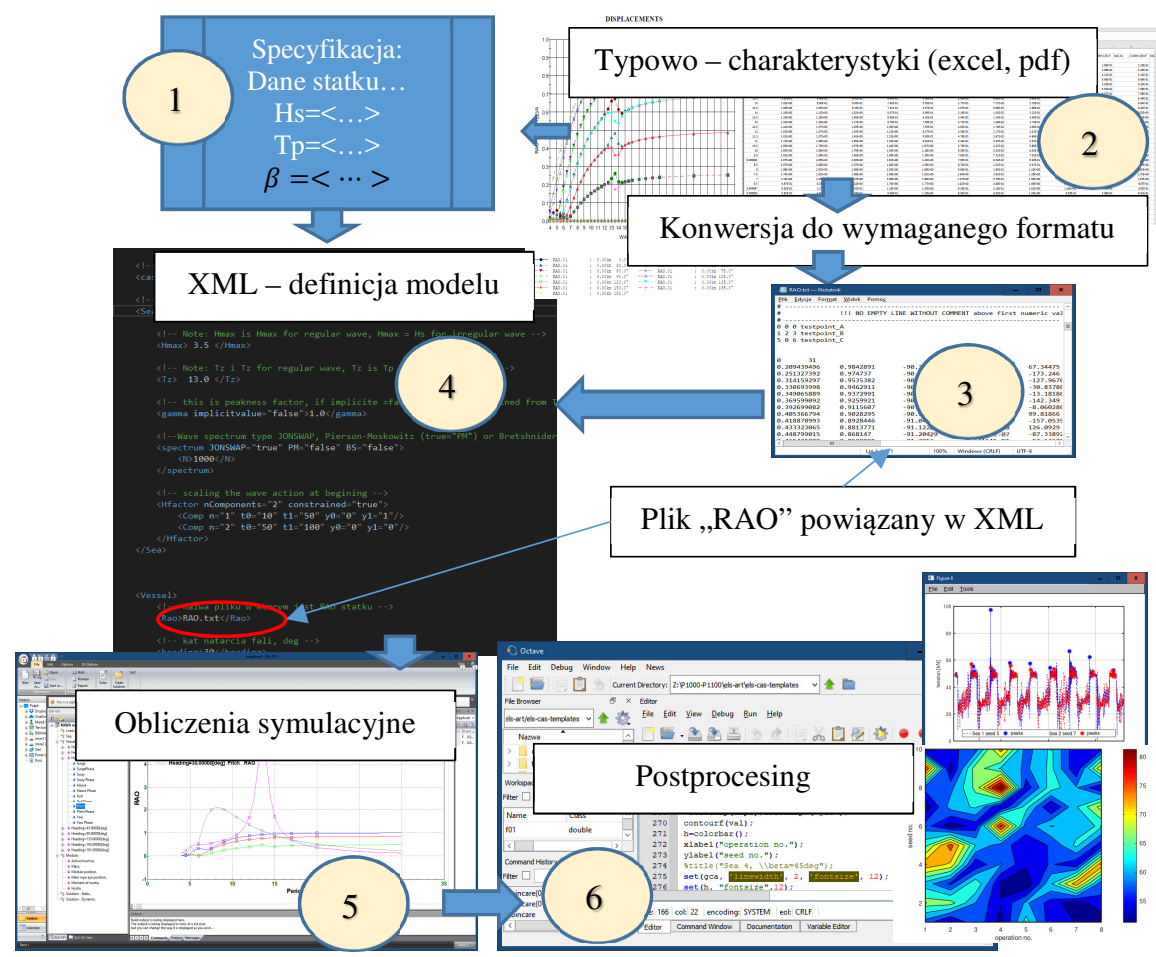

Rysunek 3. Proces prowadzenia obliczeń komputerowych

Jak wynika z rysunku 3, wymagane dane to przede wszystkim plik „RAO” oraz definicja pliku XML (dane wejściowe i sterujące do obliczeń). Program ułatwia 
tworzenie i obsługę tych plików (gotowe kreatory), a także steruje procesem realizacji obliczeń wykonując serię symulacji obejmujących zadany przedział parametrów definiujących spektrum warunków obejmujących specyfikację pracy jednostki.

\section{Obliczenia symulacyjne}

Do przykładowych obliczeń przyjęto jednostkę o długości około 180m, szerokości pokładu $40 \mathrm{~m}$, która w warunkach średniego obciążenia osiąga zanurzenie około $6.5 \mathrm{~m}$. Dla tych danych wygenerowano charakterystyki amplitudowo-fazowe, a przykładowe krzywe dla $\beta=45^{\circ}$ przedstawiono na rysunku 4 .

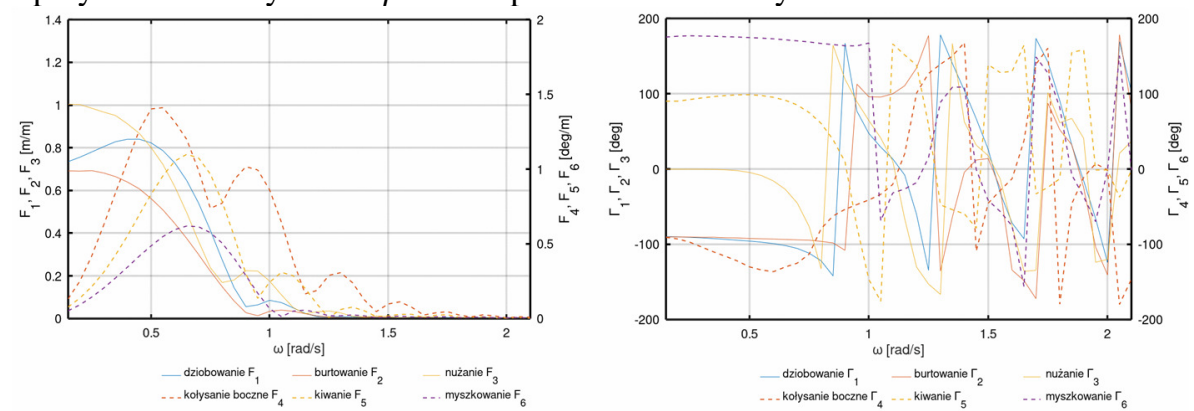

Rysunek 4. Charakterystyki jednostki dla kata $\beta=45^{\circ}$

W tabeli 1 przedstawiono założone w obliczeniach położenia oraz masy trzech testowych obiektów w różnych sekcjach statku (zgodnie z rysunkiem 1).

Tabela 1. Założone położenia ładunków oraz ich masy

\begin{tabular}{|c|c|c|c|c|c|}
\hline \multirow{2}{*}{ Obiekt } & \multicolumn{3}{|c|}{ Współrzedne środka masy } & Masa & Momenty bezwładności \\
& $\mathrm{X}[\mathrm{m}]$ & $\mathrm{Y}[\mathrm{m}]$ & $\mathrm{Z}[\mathrm{m}]$ & {$[\mathrm{kg}]$} & $\mathrm{I}_{\mathrm{x}}=\mathrm{I}_{\mathrm{y}}=\mathrm{I}_{\mathrm{z}}\left[\mathrm{kg} \cdot \mathrm{m}^{2}\right]$ \\
\hline Żuraw & -59.50 & 12.50 & 10.00 & 97800.00 & $1.63 \cdot 10^{4}$ \\
\hline Paleta & -1.25 & -10.00 & 3.00 & 2740.00 & 457 \\
\hline Kabina & 20.00 & -5.00 & 12.00 & 700.00 & 117 \\
\hline
\end{tabular}

W modelu obliczeniowym przyjęto, że podane w powyższej tabeli współrzędne dotyczą środków mas tych obiektów, a podparcie założono identyczne dla każdego rozważanego obiektu: są nimi cztery punkty rozmieszczone w narożnikach tworzących wierzchołki kwadratu o boku $1 \mathrm{~m}$ położone $0.5 \mathrm{~m}$ poniżej środka masy. W punktach podparcia zakładano elementy sprężyste przenoszące obciążenia w kierunkach osi X-Y-Z (równoległe do osi układu lokalnego statku). Założono również, iż sztywności i tłumienia elementów podparcia wynoszą odpowiednio: $1.9 \cdot 10^{9} \mathrm{~N} / \mathrm{m}$ oraz $4.8 \cdot 10^{6} \mathrm{Ns} / \mathrm{m}$, a ich wartości są identyczne dla każdego punktu podparcia, kierunku oraz obiektu (w sumie 3 x 4 × 3 elementów symulujących połączenie obiektu z pokładem statku).

W tabeli 2 zawarto przyjęte parametry falowania zastosowane w obliczeniach.

Obliczenia wykonano dla czasu $t=600 \mathrm{~s}$. W praktycznych obliczeniach czas ten musi być znacząco dłuższy, co wpływa na czas obliczeń - jednak dla celów niniejszej pracy i czytelności wyników przyjęto okno czasowe $10 \mathrm{~min}$. 
Tabela 2. Parametry modelu falowania i założony ką $\beta$

\begin{tabular}{|c|c|c|c|c|}
\hline \multirow{2}{*}{ Przypadek } & \multicolumn{3}{|c|}{ Parametry falowania } & \multirow{2}{*}{$\begin{array}{c}\beta \\
{[\mathrm{deg}]}\end{array}$} \\
\hline & $\mathrm{H}_{\mathrm{s}}[\mathrm{m}]$ & $\mathrm{T}_{\mathrm{p}}[\mathrm{s}]$ & $\gamma[-]$ & \\
\hline $\mathrm{A}$ & 4 & 14 & 1.0 & 30 \\
\hline $\mathrm{B}$ & 4 & 11 & 1.0 & 60 \\
\hline $\mathrm{C}$ & 4 & 9 & 1.78 & 0 \\
\hline $\mathrm{D}$ & 4 & 9 & 1.78 & 45 \\
\hline
\end{tabular}

Dodatkowo obliczenia prowadzono dla trzech różnych podstaw generatora losowego przy tworzeniu przebiegu fali nieregularnej wg (3).

\section{Przykładowe wyniki symulacyjne dla obciążeń pokładu}

Na rysunku 5 przedstawiono przykładowe rozkłady częstotliwościowe amplitudy fali uzyskane dla przypadku C (wykres a), dla przypadków A, B, C (zgodnie z oznaczeniem w tabeli 2 - wykres b) oraz przebiegi czasowe wysokości fali dla trzech różnych podstaw generatora losowego (g1, g2, g3), przypadek C wykres c).
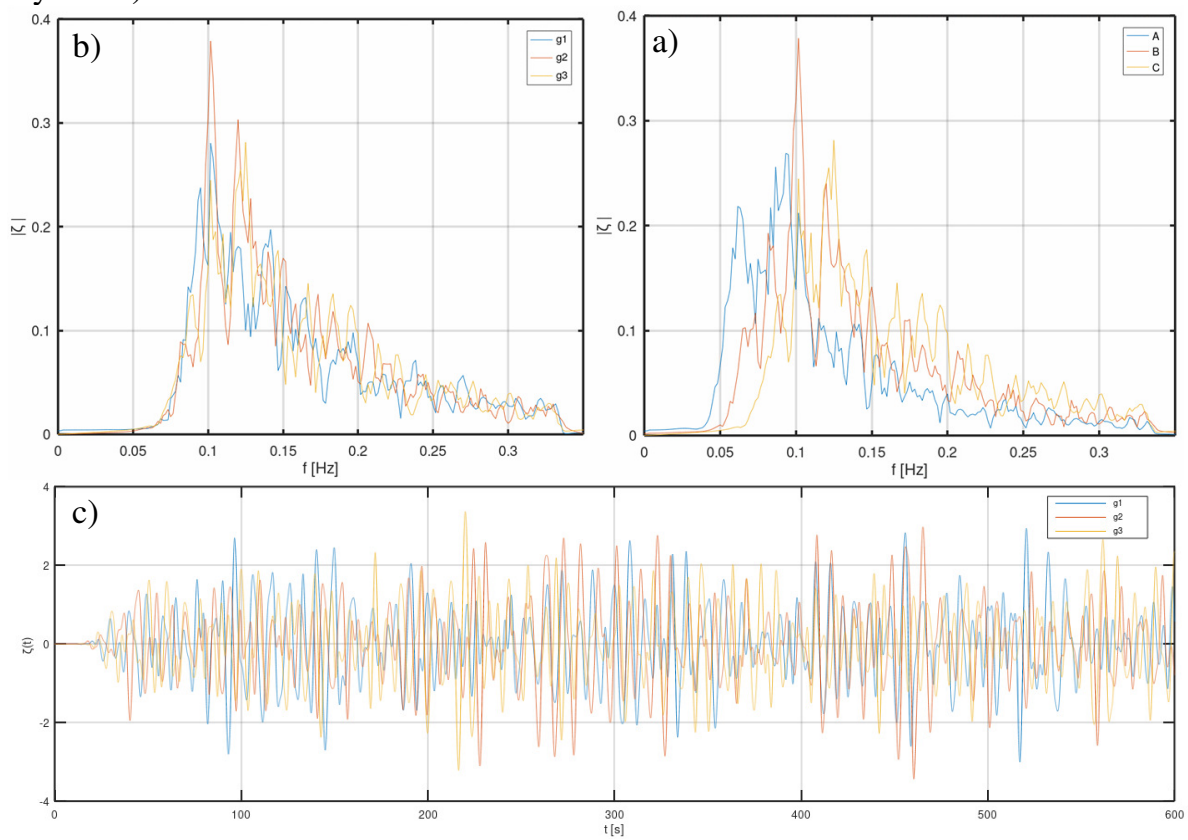

Rysunek 5. Przebieg wysokości falowania w funkcji czasu c) i częstotliwości a) i b)

Rysunek 6 przedstawia przykładowe przyspieszenia wyznaczone dla środka masy jednostki pływającej w przypadkach obliczeniowych C i D. Wykres wskazuje na wpływ kąta $\beta$ statku względem kierunkiem fali - odpowiedź (przyspieszenia) jednostki jest wyraźnie większa przy fali skośnej. 

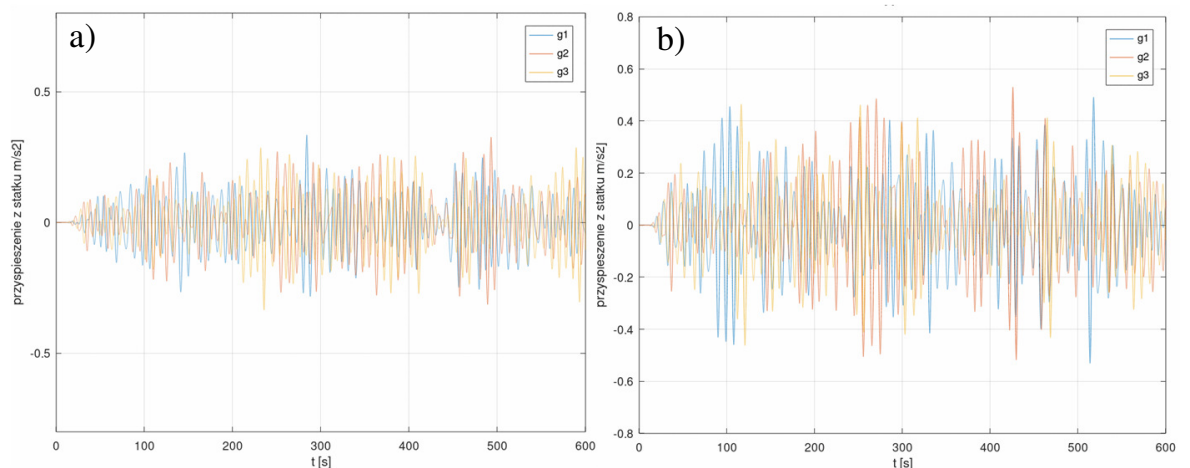

Rysunek 6. Pionowe przyspieszenie statku, a) przypadek $C$ b) przypadek D
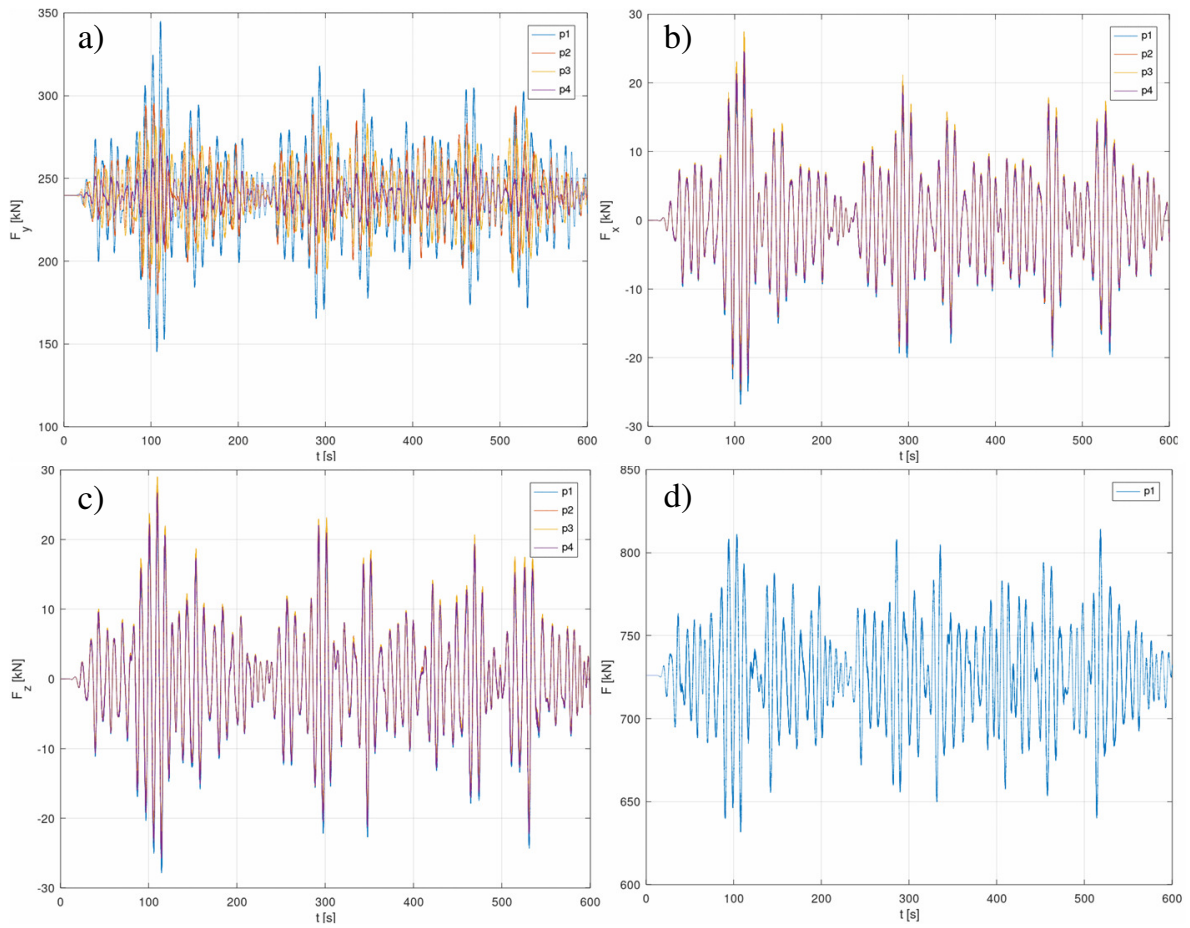

Rysunek 7. Przypadek D - przebiegi sit w punktach utwierdzenia żurawia

Na rysunku 7 przedstawiono siły w czterech punktach zamocowania żurawia, obliczone dla przykładowej realizacji falowania wg przypadku obciążenia D. Wykres d) przedstawia wypadkową sumaryczną siłę wszystkich czterech punktów podparcia.

Maksymalne reakcje w punktach podparcia dla trzech obiektów analizowanych w pracy (rysunek 1) przedstawiono na rysunku 8. Przedstawia on maksymalne siły przypadające na jeden punkt (wartości maksymalne z czterech punktów dla każdego obiektu), obliczone dla wszystkich założonych kombinacji obciążeń, działające w kierunkach układu X-Y-Z związanego ze statkiem. 


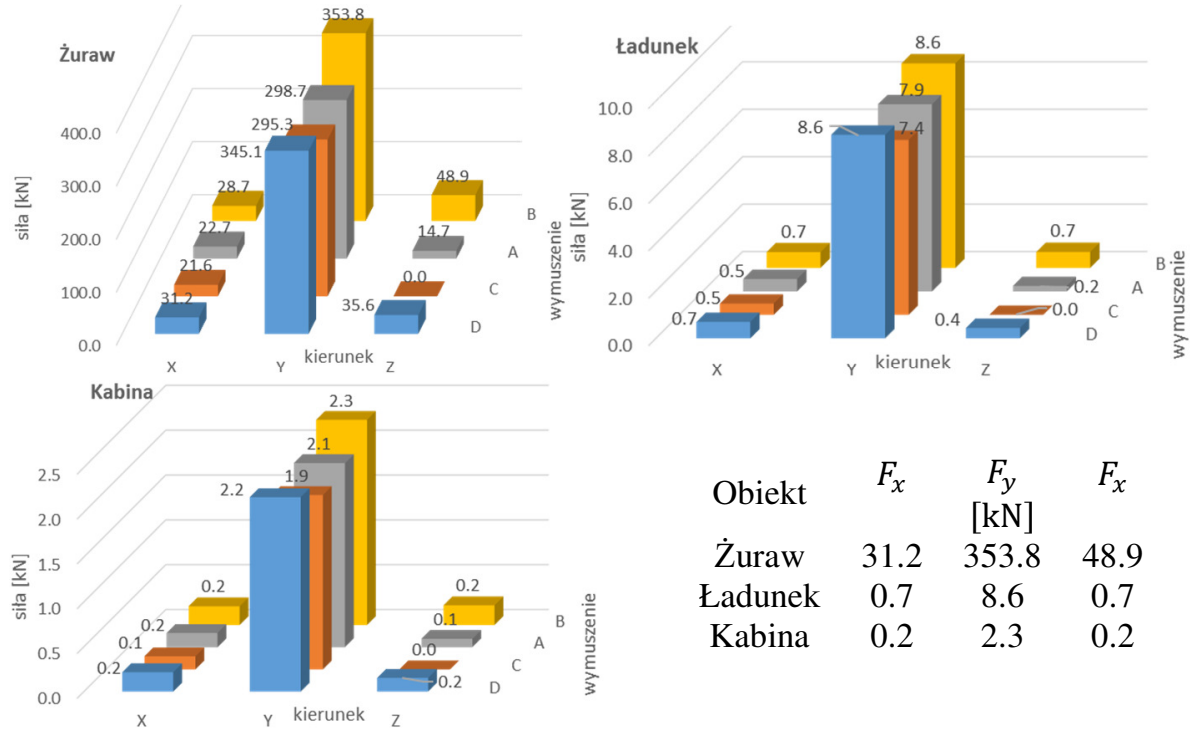

Rysunek 8. Maksymalne wartości sit reakcji w analizowanych obiektach

Należy zaznaczy, iż w pracy sprawdzono obciążenia dla wybranego stanu morza (wysokości $H_{s}=4 \mathrm{~m}$ ), a więc jednej charakterystycznej wysokości fali. Dla pełnego odzwierciedlenia wszystkich możliwych obciążeń (w tym wymiarujących), a także tranzytowych, należy powtórzyć obliczenia dla odpowiednich warunków (sztormowych).

\section{Podsumowanie}

Praca przestawia model i program, który może znaleźć zastosowanie w pracach projektowych dotyczących elementów przenoszących siły generowane w trakcie transportu morskiego. Wyniki moga znaleźć zastosowanie w procesie doboru mocowań ładunków. Innym możliwym obszarem zastosowań jest analiza obciążeń wywołanych kołysaniem zarówno pod kątem reakcji przenoszonych przez fundamenty maszyn okrętu jak również wpływu ruchów na komfort pasażerów i członków załogi okrętu.

\section{LITERATURA}

1. DUDZIAK J.: Teoria okrętu. Fundacja Promocji Przemysłu Okrętowego i Gospodarki Morskiej, Gdańsk 2008.

2. WITTBRODT E., SZCZOTKA M., MACZYŃSKI A., WOJCIECH S.: Rigid Finite Element Method in Analysis of Dynamics of Offshore Structures, Springer-Verlag, Berlin Heidelberg 2012. 